\title{
DISTANCE EDUCATION EXPERIENCES OF SECONDARY SCHOOL MATH TEACHERS DURING THE PANDEMIC: A NARRATIVE STUDY
}

\author{
Dr. Seyma SENGIL AKAR \\ ORCID: 0000-0002-0032-7439 \\ Faculty of Education \\ Kastamonu University \\ Kastamonu, TURKEY \\ Dr. Meltem KURTOGLU ERDEN \\ ORCID: 0000-0003-2438-438X \\ Faculty of Education \\ Usak University \\ Usak, TURKEY
}

Received: 30/06/2020 Accepted: 08/10/2020

\begin{abstract}
All schools in Turkey have quickly entered into the process of distance education because of the Covid-19 outbreak. In this process, mathematics teachers have become an associate of this process to teach math lessons at a distance. The subject of the current study is the experiences of teachers in this process of distance teaching of math, which is a compulsory subject in all secondary schools. The participants of the current study designed as a narrative study are 15 math teachers experienced on the subject. As a result of the study, a total of five super-themes emerged. The first super-theme includes codes related to the general structure of the math course. The second super-theme is theme of hardware and Web 2.0 tools. This sub-theme includes codes related to their experiences of EBA TV, EBA Internet and other alternative tools of distance education. The third sub-theme is the Socio Cultural super theme. This theme is consisted of sub-codes including political issues, state of the student, state of the parent and socio-economic situations. The fourth subtheme includes the codes related to psychological states arising from the extraordinary situation emerging in the pandemic (period of pandemic, cyber bullying, emotional links). The fifth sub-theme is related to the readiness of teachers.
\end{abstract}

Keywords: Pandemic, Covid 19, math teachers, narrative study.

\section{INTRODUCTION}

In the history of the world, humanity has faced many pandemics. Some of these pandemics are plague known as Black Death, smallpox, cholera, SARS, MERS and Ebola. Besides losses on a national and international level, pandemics affect countries in many ways. The new type of Coronavirus pandemic, which is thought to have emerged as of December 2019 and named as COVID-19, has spread across the world and affected almost all countries in many ways from health to economy, education to transportation. COVID-19 is a new type of infectious disease caused by severe acute respiratory syndrome coronavirus (Setiawan, 2020). With the rapid spread of the highly contagious COVID-19, countries have applied social isolation and quarantine measures to reduce the spread of the virus. Although it is known that the age group 65 and over is the age group most vulnerable to the COVID-19 pandemic, it is considered important to apply social isolation to children and adolescents, as the disease is also seen in children and adolescents and they are considered to be a carrier of the disease (Ustun \&Ozciftci, 2020). Thus, school environments where hundreds of children and young students come together have become dangerous places where the disease can spread rapidly (Sintema, 2020). For this reason, because of the COVID-19 pandemic, schools in all levels from pre-school to higher 
education have been closed in 191 countries worldwide and more than 1.5 billion students have been away from the school. However, in order for the education of students not to be hindered, countries started to search for solutions and found distance education as the easiest and most feasible solution to ensure the sustainability of education (Ustun \&Ozciftci, 2020; Telli Yamamoto \& Altun, 2020). Telli Yamamoto and Altun (2020) define distance education as a modern and effective form of learning that can be offered regardless of location and time, allowing individuals to structure educational materials electronically and integrate different technologies into the learning process. Zhou, Wu, Zhou and Li (2020) state that distance education refers to the method of content dissemination and rapid learning through the application of information and internet technologies.

Distance learning, which is independent of time and place, has gained great importance with the closing of schools and introduction of various restrictions during the COVID-19 pandemic. In this sense, it is thought that the best way to deal with COVID-19 and even the only solution is distance education for many countries worldwide (Moreno and Gortazar, 2020; Telli Yamamoto \& Altun, 2020). With the closing of schools, UNESCO recommended the use of open educational practices and platforms for education of students not to be hindered (Setiawan, 2020). In addition, they shared 10 suggestions to ensure the continuity of education: (1) Examine the state of readiness and select the most appropriate tools, (2) Be sure of the comprehensiveness of distance education programs. (3) Pay attention to confidentiality and security of data. (4) Give priority to solutions for psycho-social difficulties before teaching. (5) Plan the schedule of distance education programs. (7) Provide support for teachers and families with the use of digital tools. (8) Blend the suitable approaches and limit the number of applications and platforms. (9) Develop rules of distance learning and monitor the learning process of students. (10) Set the time for the units of distance education according to students' self-regulation skills. (11) Create groups and develop connections (UNESCO, 2020).

When all these suggestions are considered, it is seen that the main emphasis is put on the planning of technology use according to the digital skills of the teacher and students and the internet infrastructure and ensuring students' access to distance education programs. In this connection, it can be suggested that tools in computer laboratories can be temporarily shared with families. Another point emphasized is the protection of the confidentiality of the data. Then, it is emphasized that when students are isolated, groups can be formed to help them cope with psycho-social difficulties they encounter. Determination of the time and goal of distance education programs is also emphasized. It is also stated that determination of the rules of distance education together with parents and children is important. Finally, the necessity of allocating time suitable for the level of students to live broadcast lessons is pointed out and it is recommended to devote 20 minutes at most to a lesson for primary school students and 40 minutes at most to a lesson for middle school students (UNESCO, 2020).

In the relevant literature produced during the pandemic, Setiawan (2020) aimed to design and apply scientific literacy worksheets to primary school students during the period of COVID-19. It was stated that these worksheets, which are not very different from the activities in the school, were prepared to guide distance learning. The study group of the research is comprised of 35 primary school students receiving distance education due to COVID-19. When the research on distance education in the period of Covid-19 is reviewed, it is seen that most research has been done on education in health sciences. Chick, Clifton, Peace, Propper, Hale, Alseidi \& Vreeland (2020) investigated the distance education applications in the training of surgery assistants during the COVID-19 pandemic. The study focused on flipped classrooms. Conferences were given to the surgery assistants in flipped classrooms. In another study conducted on education in health sciences, Ng and Peggy (2020) focused on the visual classroom education approach to be used in clinical nursing training. The study suggests a 3-step virtual classroom training approach to support nursing educators in enhancing online theoretical hand hygiene. Murphy (2020) evaluated distance education applications in the context of the Copenhagen School and the Securitization Theory during the COVID-19 pandemic. According to Murphy (2020), while public health officials are struggling with pandemics within the scope of social isolation measures, e-learning applications will not cause a change, but will limit only face-to-face classroom interactions.

Arguing that the closure of schools and the transition to distance education have socio-cultural effects, Van Lanker and Parolin (2020) stated that the closure of schools during the pandemic affects the education of 
$80 \%$ of the children. They said that long-term closure of schools and transition to distance education may have harmful social and health consequences for poor children. First of all, it is suggested that for many students living in poverty, schools are not only a place for learning, but also for a healthy diet. With the closure of schools, many students are thought to have lost their healthy diet. The "food insecurity" that occurs as a result poses a risk for the mental and physical health of children. On the other hand, in Europe where online learning environments generally require a computer and a secure internet connection, a significant number of children live in homes that do not have the appropriate place to do homework $(5 \%)$ or do not have internet access (6.9\%). In another study with similar results, Alpago and Alpago (2020) investigated the socio-economic outcomes of the coronavirus epidemic, and stated that the use of digital education options differs by regions and individuals with different economic conditions. While it is emphasized that digital platforms such as Facebook, WhatsApp and Google have the potential to open online education schools, rural schools in rural areas and families living in houses with a lack of technical infrastructure may be negatively affected by this situation. Zhou et al. (2020) focused on the "School's Out, But Class' On" project launched by the Chinese government. The focus of this project is an online teaching path aimed at broad-based learning. According to Zhou et al. (2020), broad-based online educational activities need to be guaranteed by a well-established Internet infrastructure, and without this strong infrastructure, largescale online educational activities cannot be carried out. And it is stated that China has guaranteed largescale online educational applications as a result of thirty years of work to establish the necessary internet infrastructure.

Along with the compulsorily initiated distance education process, many courses are carried out in online learning environments and using various teaching management systems. Many students and teachers have faced such a situation for the first time. Although the increase in online learning opportunities makes it possible for students to access online courses, this rapid growth also brings quality problems (Ferguson, 2020; Patterson \& McFadden, 2009). This holds true for mathematics education. Xu and Jaggars (2014) stated that for students it is more difficult to be successful in online math lessons than face-to-face lessons. When the existing research is examined, it is seen that online learning environments are at least as effective as face-to-face learning environments and although there are many benefits for both students and teachers, this seems not the same for mathematics lessons (Ferguson, 2020). In their qualitative study on math teaching, Ferguson and Smith (2005) stated that teaching mathematics in e-learning environments does not work very effectively. The results of their study revealed that there are real difficulties in online math classes.

There are two extreme views regarding the conduct of all mathematics courses online. One view argues that it will be effective to have the lessons completely online while the other states that it is not possible to conduct an effective mathematics teaching completely online (Trenholm, Peschke \& Chinnappan, 2019). Trenholm et al. (2019) emphasized that although in the studies comparing face-to-face and online mathematics lessons, it is claimed that there is no difference in terms of teaching and learning, this claim is incomplete because in these studies, the success criteria consisted of the results produced by tests. In addition, in these studies the success is not clearly defined and whether the tools used are reliable or valid is not clearly stated. This is not effective and sufficient to interpret the nature of learning (Parker \& Gemino 2001; Micari, Light, Calkins, $\&$ Streitwieser. 2007). Based on this, Trenholm et al. (2019) stated that online learning is still very new and should only be used to support face-to-face learning.

Given the delineations above, it can be said that teachers and students are the people most affected in the distance education process, which was mandatorily initiated because of the pandemic. The studies in the relevant literature seem to be largely focused on students, learning process and the determination of the existing state. Thus, how this process works in terms of mathematics education is one of the subjects that should be investigated. As the most important element of the process, teachers' experiences and observations in this process are also important. Therefore, a study aiming to reveal what the teachers have experienced as a result of the pandemic can help fill the void in the literature. In addition, with the current study, it is aimed to take a detailed picture of the distance education process in this extraordinary period from the perspective of mathematics teachers. In this regard, the purpose of the current study is to investigate math teachers' experiences.

The review of the literature should be up-to-date, comprehensive and address the need for the manuscript. should be up-to-date, comprehensive and address the need for the manuscript. 
Paragraphs should be neither too long nor too short; each paragraph should be longer than a single sentence but no longer than one manuscript page. The manuscript should be prepared according to the Publication Rules of the journal. The style of the text should be 11 Point Adobe Garamond Pro, Black and Regular.

All figures should be numbered using Arabic numerals. Figures should always be cited in text in consecutive numerical order. Figure parts should be denoted by lowercase letters. Each figure should have a concise caption describing accurately what the figure depicts. Captions should begin with the term Figure and continue with a figure number. No punctuation should be placed at the end of the caption. The authors should identify previously published material by giving the original source in the form of a reference citation at the end of the figure caption. Figure size should fit the column width of the journal..

\section{METHOD}

The purpose of this narrative study is to explore the experiences and difficulties of teachers who had to be suddenly involved in a distance education process in line with the measures taken during the period of the epidemic in Turkey. In this context, the study was designed according to the narrative research model, one of the qualitative research models. Narrative studies are specialized studies including the analysis process of life stories (Clandinin and Connolly, 2000). According to Creswell (2013), narrative studies focus on the stories narrated by individuals and the experiences they have lived.

The current study aims to understand the story of teachers involved in the process of distance education without having much experience about it and to investigate their experiences on the basis of their stories. Therefore, the current study was constructed as a narrative study.

\section{The Situation in Turkey and Participants}

The first Covid case was announced in Turkey on March 11, 2020. Then as in the rest of the world, formal education was suspended until 30 April 2020 with the announcement made on Thursday, March 12, 2020 within the scope of the health measures taken in the country. As of March 23, 2020 all students in Turkey have been involved in distance education primarily through EBA TV and EBA Web. Then, with the increase in the number of cases, the process of suspension of the formal education at schools was gradually postponed to $15 \mathrm{May}$, and then it was announced that schools would not be opened in this term (MEB, 2020).

As summarized above, it is seen that all teachers and students entered this process without any preparation as a result of the measures taken during the epidemic. After the statement made on Thursday, students and teachers who went to their schools for the last time on Friday left the schools think that they would return to school soon. In Turkey, 3.2 million students and hundreds of teachers experienced a sudden and huge change in their lives and accordingly in their education lives. All teachers and students tried to adapt to the distance education process that started firstly via EBA TV and EBA Web within a week they spent at home. EBA TV is a television broadcast with short lectures at different times. In these video broadcasts, teachers often deliver the 20-minute lesson in the form of lecture. EBA Web, on the other hand, is a website which is designed for computer-assisted teaching and where each student can have access to content over the internet. Teachers and students access the website with their own passwords and usernames. Teachers can allow students to have access to any course content on the system. These contents include video-based animations, game-based activities and worksheets with math problems. Teachers can monitor students' progress by following their individual studies on the web.

Chain sampling was used in the current study. Chain sampling is one of the purposive sampling methods. In this sampling method, it is started with a person who meets the criteria determined and other people who are recommended by this person and meet the criteria are added to the sample (Patton, 2018, p. 237). A total of 15 teachers participated in the current study. All the participating teachers are the graduates of secondary education math teaching departments in education faculties of good universities of Turkey. The professional experience of the teachers vary between 1 year and 15 years; that is, all the participating teachers graduated from their faculties after 2005, which means that all of them were introduced to the computer and technology at early ages. All the teachers are working in the state schools of the Ministry of National Education. All the teachers took at least one computer-assisted mathematics education course during their undergraduate education. All the teachers participating in the current study define themselves as prone to 
technology and voluntarily involved in the study on the recommendation of another teacher friend. All of the teachers are known as positive and hardworking teachers who try to reach their students in the distance education process. Therefore, the criteria used in chain sampling are; years of teaching experience (1-15 years of teaching experience), being prone to technology, positive opinions and recommendations of other teachers, volunteering, mastery on EBA TV and EBA Web contents, and being a stakeholder in the distance education process.

\section{Data Collection, Analysis and Coding}

The data of the current study were collected by telephone in April 2020. In the data collection process of the current study, a semi-structured interview form was developed and an approximately 25 min. ongoing interview was conducted with each participant. In the interview form, there are items to elicit the participants' experiences of distance education in the period of the epidemic. The interviews were recorded with a voice recorder. While conducting the interview, the researcher tried to follow a systematic way. At the end of each interview, a preliminary analysis was conducted and researcher notes were taken. When needed, the interviewees were re-contacted. The data obtained from the interviews were transcribed simultaneously with the data collection process. These transcripts were coded by using Maxqda program and analyzed by using the content analysis method.

\section{Credibility, Transferability and Dependability}

In order to ensure the dependability of the study, the researchers analyzed all the data in two different time periods individually and then compared their analyses. After all the codes were established, the sub-codes were determined and then the codes were revised. In order to ensure the credibility of the study, while developing the interview form, a conceptual framework was created by examining the relevant literature. While these interviews were going on, the data obtained from the interviews were confirmed by the participant confirmation method by asking questions such as "is it like this?", "have I understood correctly?" After the interviews, the participants' statements were analyzed and these analyses were confirmed by the participants and finally, all the data were first analyzed by the two researchers together and then individually. In order to ensure the transferability of the study, the findings obtained in the data analysis are given in detail by the direct quotation method without any comment. What has been done in the process is explained in detail. In order to ensure the dependability of the study, the raw data and analyses obtained are stored by the researchers so that they can be examined by others for a possible confirmation in the future.

In terms of ethical dimension, the most important priority of the researchers is the confidentiality of the participants. The content of the study and the research questions were shared with the participants by e-mail before the interview. The participants were verbally re-informed about the study's framework and ethical codes before the study and their consents were gained through voice recording. After the completion of the reporting process, the full text was shown to the participants and the publishing process was initiated after their approval was received. All the participants are coded as T1, T2, T3 and no data is given within the study to reveal the identity of the participants.

\section{FINDINGS}

As a result of the analysis of the interviews conducted with the participants, "five super themes" emerged. Super-themes contain different codes in themselves. Related codes come together to form super-themes.

The first super-theme includes codes related to the general structure of the math course. The second supertheme is theme of hardware and Web 2.0 tools. This sub-theme includes codes related to the teachers' experiences of EBA TV, EBA Internet and other alternative tools of distance education. The third sub-theme is the Socio-cultural (Inequality of opportunities) super theme. This theme is consisted of sub-codes including political issues, state of the student, state of the parent and socio-economic situations. The fourth sub-theme includes the codes related to psychological states arising from the extraordinary situation emerging in the pandemic. The fifth sub-theme is related to the preparedness of teachers. Opinions of each participant can be included in more than one code and super-theme. After the findings of the current study were analyzed as a whole, they were separated into themes and reported. 


\section{First Super-theme- Delivery of Math Class}

In this super-theme, opinions from 15 participant teachers are given. In this context, the teachers' opinions about live lesson content in their distance education experiences were collected. These opinions were gathered under the codes such as problem solving, classroom discourse, using materials and different teaching methods. These codes are explained in the order specified above.

\section{The Problem Solving}

The problem solving process is undoubtedly one of the most important components of mathematics teaching. Teachers emphasized that students' problem solving experiences were restricted especially during the distance education process. The teachers stated that in all the lessons delivered over EBA TV and EBA Web, students were put into a passive position.

The greatest harm has been given to mathematics in this process. In mathematics, the child should write the question and think over it. Helshe should solve it step by step, try to solve it. Helshe should think about $i$ it. Helshe should discuss the problem with others, should listen to others' opinions. If it is necessary, we need to explain it step by step. It does not happen so in this process. There are videos in the internet and on TV. They watch the video like watching a film. Helshe should be personally involved, solve the problem, think about it. Helshe can watch videos to see his/her shortcomings but only after helshe has solved the problem; in my opinion, mathematics cannot be learned from TV or videos. It does not happen without thinking and using pencil. Mathematics is a mental process not a film. The student just watches it. (T1)

Mathematics requires students to make efforts. They need to solve problems. In this process, particularly in the parts involving learning from $T V$, they just listen from $T V$. They are passive. Even if I teach on $T V$, the same will happen; they will just listen. Lessons are visualized but there is no mental process involved. The student needs to spend time with mathematics; in the application stage; in the problem solving stage. Thus, some time needs to be given to students; the teacher needs to be with them. But here we cannot give time. Does the child solve the problem by pausing the videos? What will the child do? In distance education, it is also difficult to manage time. Time is more limited in distance education. (T9)

Mathematics is not verbal. It does not occur in the form of lecture and show. In this process, the only technique used is presentation. We use free applications. There, limited time is given. I solve the problem on the screen and students watch me solving the problem. Therefore, we feel really restricted. I think I cannot give enough time. Live lesson environment is not like face-to-face teaching at school. I am lecturing and students watch the video; this is not mathematics. The student should solve the problem and I need to watch him/her solving the problem and I need to intervene when needed. In Zoom, students respond altogether. For example, one student says I have done it by writing on Chat but I cannot see what helshe has done. In this process, I am not next to the student, I cannot see what helshe is doing, whether helshe is doing true or false and where helshe has a difficulty. Otherwise, helshe would easily progress easily with my help. Here, as students are in a group and I cannot see them as I see in the class, I cannot intervene with individual students. If I ask many questions to a student, helshe may feel worried. (T5)

\section{Classroom Discourse}

In the interviews conducted with the teachers, the teachers stated that they had difficulty in establishing mathematical communication with students especially in the live lesson process in distance education. The teachers emphasized that classroom discussions are not sufficient and productive.

Mathematics is a subject against which students are already prejudiced. You need to establish an emotional contact with the student. When it is face-to-face, you can talk their language and you catch them. You get feedbacks from students and you can involve them in the process. In a face-to-face lesson, there occurs classroom discussion and communication. This is the most important thing. In this way, they are only listening in the synchronous lesson; if you allow them to speak, then it leads to confusion. We cannot turn on the voice for all students. There are very creative children; children offering different solutions and ideas. Even I get very surprised sometimes as they find a different solution from a different perspective. Thus, there is no interaction in a live lesson because they are just listening. (T4) 
When you say "you understand?" in the classroom, sometimes there is no sound, but we can understand whether they understand even from their facial expressions. You see everyone on these kinds of screens, but you can't notice everyone, you can't focus. They are also hesitant; there is no reaction. They do not respond when I ask a question. There is no communication. Only when one of them dare to speak is there some communication; some reaction. Even when they want to talk, as there are many students, you cannot understand who is saying what. To prevent this, their microphones are usually off. In this way, in my opinion, math teaching is not efficient. If we were able to teach one-to-one, then it might be more successful. (T6)

\section{Using Materials}

Only one of the teachers stated that he/she was doing activities using an interactive material during the lesson, but had problems in this process. The experience of the teacher regarding the use of concrete manipulative materials is given below.

There are also restrictions on material. In geometry for example. There is the subject of bisector, something like median line. There is the paper folding activity. I would have liked to do this activity as it is relatively simple. I was able to show it in a video but I need to see the child folding it. I show the paper on the screen and tell students "Put the two concerns on the top of each other. But they hold the wrong corner. I say "Put them on each other". Yet, some ask "Which one?", "It does not happen". I describe it but I cannot correct it with my hand. If I were next to him/her, it would just take 30 seconds; but, here it takes minutes. For example, if we construct an object. The same problem. I would like them to have concrete materials in their hands. I would like them to construct but it is not possible from distance. (T5)

\section{Different Teaching Methods}

Most of the teachers stated that they had difficulties in using different methods with students in mathematics during the distance education process. They emphasized that many methods (e.g. Drama, Gamification) they use in the classroom cannot be used in the distance education process.

At the first level, you can provide information at the level of understanding. How do you solve new generation questions (teacher means Timss, Pisa questions). For example, you are teaching whole numbers. You move two steps forward, one step backward. Sometimes you are joking, playing roles (Drama method). How can you do these? You cannot. (T2)

I normally use concrete materials and games in my classroom. I actually play a lot of games. I like mathematics games and many of them are games that should be played in pairs. I cannot figure out how to do these here. I cannot use any different methods in this distance education. I am the only active person. It is just lecturing. (T7)

\section{Second Super-Theme - Tools of Distance Education}

Under the second super-theme, the experiences of the teachers with the distance education tools they use are described. A total of 4 different codes were obtained under this theme. The first of these codes is EBA TV, the second is EBA Web, the third is Web2 tools, and the fourth is WhatsApp. One of the interesting findings related to these codes is that the application that teachers use most in the distance education process is WhatsApp. Thus, a separate code was created for WhatsApp and this code is given below.

\section{EBA TV}

In this process, teachers need to follow the lessons on TV, construct the lesson in accordance with the course contents and create assignments and activities via EBA Web. Teachers stated the following views regarding the contents of the TV video watched by students in this process. 
I thought that they would not understand at all if they watched Ebatv. The teacher was reading mathematical problems by opening the slide on TV. It was completely incomprehensible. Then it was improved. It became a lesson in which the teacher was writing and teaching gradually. Now, we are watching these lessons. We are expected to present a content parallel to these lessons. But I thought. We are normally solving many problems like this in the class and teach them many times. In this way, students seem to not understand anything. The teacher only teaches once; this is not enough. On TV, it is not possible to rewind it. There is no chance to watch it again and when you watch it, it lasts just five minutes and there is no other way of teaching. Thus, TV seems to be problematic. On the other hand, there is teaching in the form of simple lecturing. (T4)

There are videos in the internet and on TV. Students watch the video like watching a film. Helshe should be personally involved, solve the problem, think about it. Helshe can watch videos to see his/her shortcomings but only after helshe has solved the problem; in my opinion, mathematics cannot be learned from TV or videos. It does not happen without thinking and using pencil. Mathematics is a mental process not a film. The student just watches. Videos particularly the ones presented on TV last just 20 minutes. The objective I normally spend 5 class hours in the class to teach is tried to be taught within just 20 minutes. In this process, the child can only see the solution of one problem and helshe will not have any support next to him/her. This is also problematic. If I were able to teach one-to-one in this process, it might be effective but in its current form, it is not. (T1)

\section{EBA Web}

The teachers' experiences in this process are gathered under two sub-codes. One of them is the problem of access to EBA Web. The other sub-code is the content of EBA Web. Most of the teachers reported many positive opinions about the content of EBA Web. However, the content of EBA Web could not be reached by all the students in Turkey at the same time as the capacity of the server was not enough for this; thus, many of the students could not have access to the contents. Related experiences of teachers are given below.

\section{EBA Web Content}

Most of the teachers reported many positive opinions about the content of EBAweb:

I have been using EBA Web for a long time. It is an interactive environment and I think that it is not appreciated as much as it deserves. If EBA were used properly, it would be a platform suitable for creating a lesson plan. I am developing my lesson plan as follows: First I look at videos, activities, tests and then I select them and order them. I put them in order of priority. I order them in my lesson plan. When I start my lesson, I use my plan. Children can see my lesson plan. We can give tests to students; there are gamebased activities and we can also give them. After teaching the subject, we can use the activities. We can also see how much of the homework assigned to students has been done, how they have done it and how successful they are. We can add files ourselves if we want. We can create our own exams. We can monitor their work. I personally like it very much. I normally use it. I wish students could reach, but they can't. (T13)

First, I wanted to run it over EBA. Actually I think their ready content is very nice. There were activities I used in my normal class. There are very nice contents for students to comprehend the subject. I think it appeals to all children at the level of understanding. There are good contents to make students comprehend the logic. (T1)

I wanted to use EBA and to teach a lesson over it... I even thought I would upload videos to EBA, but there are many limits for video contents to be uploaded. Therefore, I gave up. Also, the children could not $\log$ in even if they were allocated certain hours to enter EBA. They continuously logged out the system. They could not enter at all. The internet connection was also problematic. In my village, there is also the problem of electricity. There occur some power-cuts when there is a storm. And when the system was overloaded, the server could not manage it. Children could not enter at all. So we had to find alternative ways.(T7) 
Although most of the teachers stated positive opinions about the contents of the EBA Web platform, some teachers stated that some of the EBA contents were below the level, that they did not suit all students and that some of the contents did not serve the purpose.

There are activities that can create misconceptions in eba. I cannot exactly remember right now. I even wrote a report about them. Unsuitable contents. I am actually using but in a selective manner. They are not always suitable. Some activities are inadequate. Some activities do not serve their purposes. For example, there is a video about the running speed of dinosaurs. Video is actually very interesting content. There's a dinosaur called Gallamouus. Students are asked to create an algebraic expression about the running speed of this dinosaur. When I saw it, I thought this content was very nice. But there the child focuses on the dinosaur and his name and shape etc. What is its name and how is it running etc.? It is a remarkable content, but it did not have the desired effect on children. Children could not focus on the algebraic expression. Rather, they entirely focused on the dinosaur, yielding reactions from students such as "The word is very long. Was it really like this .." etc. The content of EBA; content that we will give to children needs to address the reality of children. Of course, this is not true. There is another situation as follows: There is a video about percentage calculations. There is a reduction by 20\%+30\%. One character in the video says there is a 50\% discount in the store. With another character, they discuss how it should be calculated if it really is 50\% discount. They calculate. Then they tell the percent of the discount. Actually, that content seemed dull to me. But it appealed to the real world of children. Although not all the contents are suitable, there are some suitable ones. And through this video, the children realized that they should not sum the percentages directly. They won't forget. I mean, activities should be used selectively. (T4)

EBA content is bad. It only appeals to some of my students. Videos can be used to teach the basic meaning of a concept at the level of a simple introduction activity. Simple contents in videos; they do not appeal to good students. They are below the level. For example, there are no new types of questions (similar to TIMSS, PISA contents). (T6)

\section{EBA Web Access}

All the teachers we interviewed stated that there is a problem accessing the EBA web site. The teachers who stated that there was a problem in their own access stated that almost all of the students had access problems.

We tried to follow the students over EBA but frankly it did not work. As the server was overloaded, it could not manage it. Students cannot connect the internet in the hours they wish. As there was also time limitation, they could not do it. They are always complaining. (T3)

I wanted to use EBA and to teach a lesson over it... I even thought I would upload videos to EBA, but there are many limits for video contents to be uploaded. Therefore, I gave up. Also, the children could not $\log$ in even if they were allocated certain hours to enter EBA. They continuously logged out the system. They could not enter at all. The internet connection was also problematic. In my village, there is also some problems with electricity. There occur some power-cuts when there is a storm. And when the system was overloaded, the server could not manage it. Children could not enter at all. So we had to find alternative ways. (T7)

I have students from $6^{\text {th }}$ and $7^{\text {th }}$ grades and there are 20-25 students in each class and only 7-8 of them could have access to EBA. We can see the students who can access the system; they can do something there and make some progress. But they had some great difficulties. They are always complaining. Most of the students could not access. The system always makes them logged out. Although it is a bit better now, still there are serious problems. (T12)

\section{WEB 2.0 Tools}

As students and teachers could not access EBA, which is seen as the most important tool and resource in the distance education process, they turned to alternative Web tools or communication tools. Some of the teachers use programs such as "derslik", classjodo. Besides, almost all of the teachers try to use live lesson tools. 
We looked for an alternative when we had a problem with EBA. I'm using classjodo. I recorded all the classes. It gives feedback to children such as how many students participated, did their homework, etc. All the students can see what others did or did not. Parents can also see them and thus there is a good competition among students. Even I assign homework via eba I also announce it from here. But in any case, although I have 225 students, only 30-35 of them participate. In fact, I am using different sources. I am using the activities in the internet sites of NLMV. There is also another webpage called "Derslik". I share sources there. There are Youtube channels. There are many channels in English. I am sharing activities from there but only 2 students complete them. They do not want to do them as they are in English but in fact everything is quite understandable. I wish there were such sites in Turkish. (T4)

I have also checked; there are problems of access. I searched for 15 days to find out what I could do. Then I decided to use Zoom. It allows you write on the screen. It does not want anything extra juts an Ip. Screen interaction is better in Zoom. It allows writing on the screen via a tablet or telephone. I made a search on the internet to find out how to write on the screen. I have learned a pen could be made by covering an ear stick with aluminium foil. I made all the children do this. Now they can also write on the screen. They can do this on the phone. They can better interact. You cannot see the children; my screen is active. I solve problems and revise the subjects. As they have limited internet access, I do not make them turn on their screen. They have just their voice. I sometimes ask; sometimes they themselves tell something. (T13)

When I realized that EBA is not effective, I looked for another program. Then I started to use Zoom. I do not have a graph tablet; I share the screen and try to write by using the pen of the program. It is not much efficient in fact. I am preparing in advance or using ready-to-use materials. It can be difficult for children to take notes at the exact moment because we cannot wait for long because there is a time limit in free programs. I revise it once more then I send the materials to them (T8)

\section{WhatsApp, as a Tool of Distance Education}

When teachers could not communicate with their students via EBA Web, and as a result of the difficulties experienced by students in having access to EBA Web, all of the teachers stated that they used WhatsApp as an alternative communication channel. In Turkey, middle school $8^{\text {th }}$ graders have to take a central exam and according to the result of this exam, they are accepted to high schools. Teachers use this software as a distance learning tool, especially in order to respond to the problems of $8^{\text {th }}$ grade students quickly and to respond quickly to the needs of students.

I am using WhatsApp. We founded a group with the students who would take the exam. There are just 10 students. They send their problems to me. I solve them, take the photos of solutions and then send them to students. If it's a multi-step question, I'm shooting a video. They generally clearly understand them. (T11)

We have class groups on WhatsApp. I assign homework daily. I spare time for my students individually in the evening. They say "I could not do, could not understand". We are making video calls. I solve it by writing and then send its video. I spend 4-5 hours in this way every day. During the video call, I show the student what I have written for him/her. I am always in short lessons but this requires personal effort of the students yet not all students are willing to do this. For example, there are just 6-7 students from my eight graders. Others are silent. I cannot force them in the distance education. Students who take the exam seriously are more willing. (T6)

Teachers state that using WhatsApp as a distance learning tool creates some technical difficulties and application difficulties.

We send works that are tiring for me and students and announcements on a single channel via WhatsApp. There are at least 100 messages per day in a single message group. I have at least five groups. It is also difficult for students to follow these messages. While I am doing something, a message comes. It is good to be in contact but there is no time limit. Even at night, students can send messages to ask questions. We are always checking our telephone, day and night, to see whether there is any question from students, there is any announcement. (T5) 
As we could not work via EBA and some students do not have computers we are using WhatsApp. In fact, this is also a problem because the child must check it from his/her telephone. This is also problematic. Hel she does not have a telephone and there is no printer at home. Even we do not have a printer at home. Although my husband and I are teachers, we do not have a printer at home. I do not know how a student can handle this. (T12)

The child asks a question in the morning. I can respond only in the afternoon or evening. Then the child can see the answer next morning. Thus, there is a time problem. You can't answer instantly. You can't always go directly into a fast communication process. The child may have even forgotten the question. (T14)

\section{Third Super-Theme- Socio-Cultural Factors}

Under the third super-theme, the teachers' experiences arising from the socio-cultural situations of the students are included. All the codes in this theme reveal the differences and inequality of opportunity among students and disadvantages some students experience. Sub-codes under this theme are socio-economic status, parent profile, student success in the classroom, student readiness, distance education policies.

\section{Socio-Economic Status}

First of all, all the teachers stated that they could only reach a limited number of students. The ratio of the students who could continue their education in the distance education process remained between $20 \%$ and $65 \%$. According to the teachers, the main reason for this is socio-economic.

Everyone was on the internet during this period. Internet infrastructure could not bear. Infrastructure is not strong enough. And not everyone has equal conditions. Students access the internet on the phone. The child has an 8 GB internet package but when helshe downloads 1 video, most of it has been used. There are some houses where there is one telephone but three children. There is 8 gigabyte (GB) internet in this one telephone; naturally, these children stay outside the system. We cannot reach these children. (T7)

The child does not have a computer. Helshe does not have a tablet, either. They only have their parents' telephones. They do not have unlimited internet packages. I heard a parent complaining about the telephone bill, which was 300 TL last month. How can they pay such bills? They cannot have internet connection at home. There are 3-4 children at home, so how can they manage the process with just one phone?(T9)

I have already delivered several lessons and 20 students from among 30 students were able to participate in these lessons. Not everybody can participate. This is a problem. Not everybody has a computer. Thus, they use their parents' phones. There are some students who cannot even reach their parents' phones as their parents are working. And as their siblings are using the phones available, some students cannot even find a phone to connect. Some cannot participate as they have internet problem. None of them said "I do not want"; in my opinion, they cannot participate as they do not have the required conditions. But I cannot do anything. (T8)

I personally take distance education more seriously in eight graders. In my one class, there are 12 students and in another, there are 16 students. But 7 students from among 12 students in one of my classes, and only 8 students from the other class participate in lessons. I am working in small groups. The children living in village school lack the required opportunities. They are already connection via a telephone. The students who are most active are those preparing for High School exam. Their motivation is higher to participate. They are somehow solving the problem of internet. Some students miss some lessons as they do not have internet connection. Then they participate again when they find an internet connection. (T13)

\section{Parent Profile}

The distance education process is a process that children spend at home with their families. In this regard, the primary guide of students at home is now their parents. The teachers' experiences have revealed that the most important difficulty for parents is to handle both children's care and educational responsibilities. In addition, according to the teachers, parents' educational status is the most important factor making students advantageous or disadvantageous in this process. 
Children are completely our responsibility at school. Now most of the responsibility is on the shoulder of parents. In this process, students having educated parents are more advantageous. More importantly, the children of parents caring for their education and the children supported by their parents come to the fore in this process. Some parents are completely indifferent to their children in this process; their relationships with the school are bad and the children of these parents almost never participate in lessons. (T10)

There are 3-4 children in the same house. How can the needs of these children be met? Which of these children can the mother support? For each child, there are different WhatsApp groups. She should follow all these groups for her children. It is a complete mass. There are many courses. Although I have just one class, I cannot follow the messages sometimes. How can a mother handle all these? Moreover, if the mother is not educated, then it can be a disaster. Naturally, they remain out of the system. I can only reach 20\% of them. (T9)

Parents have great difficulties. They cannot manage the process. For example, a parent has three children. She sent one of the children to his/her aunt. People at home are always arguing and she cannot deal with this. Here the greatest responsibility is on the shoulder of parents yet parents do not exactly know what to do. On the other hand, some parents really want to support their children but they do not know how to do this. Thus, these children can be misdirected as their parents do not know how to monitor the process and what to do. It is also difficult to teach them what is correct. Educated families manage the process better. Others cannot. (T3)

In addition to the above-mentioned negativities, it is observed that the negative behaviours that children are exposed to at home depending on the parents' situation are directly affected by the process. In this regard, one of the teachers explained her opinions as follows:

I think that parents are in a difficult situation because their children cannot go out and to school and have to stay at home. There are many children experiencing problems in the family. Many children are in traumas. When they come to school, they get away from home and socialize with their friends. But now, mothers and fathers are at home; children are within conflicts. Everyone says, while they are altogether, there are more conflicts. Parents are fighting and children are exposed to this. Everyone has more important problems now. When children go to school, they are away from this environment. There are quarrels at home. You try to learn something from the lesson taught in Zoom while your parents are quarrelling at home. This is quite difficult. (T2)

\section{Students' Success in the Class}

This code points to the math success of students in the class. All of the teachers stated that students with low success level in the class either did not attend at all or did not continue in this process of distance education. Based on their experiences in this regard, teachers expressed their opinions as follows:

The level of the student has become more important in this process. Students who are very good or good successfully continued in this process. They are fulfilling their responsibilities. They rarely need us. Good students succeed in any case, being in the class or online. We cannot reach students of low level. On the other hand, the child seems as if helshe was listening in this distance education but in fact nobody knows what helshe is doing. I have great difficulty in drawing their attention even in the classroom; here it is much more difficult. Students having auto control seem to be more advantageous. (T12)

Children have the fear of mathematics. In math, the feeling of failure is more prevalent. Therefore, children who reach us and children we can reach are generally successful students. They are already successful at school. In this process, the children who were average or below the average in the class got completely lost. They got more passive. Children who needed little support to progress in the class cannot find this support here; thus, they are getting worse. They try a bit and when they experience any failure, they can easily give up. (T8)

I also deliver live lessons. It is better than just uploading videos. I connect my phone to the computer; thus, at least we have some communication, of course quite limited. If it goes on like this, we can completely lose some students. I had already difficulties in involving these students in lessons in the classroom environment. Yet, they completely got lost in the distance education environment. Now, I am teaching the same lesson 
to all the students at the same time. When we were in the classroom environment, I used to give easier questions to the students below the average. I also used to give them extra support while others were solving problems. In this virtual environment, the child hides himselflherself. In the classroom on the other hand the whole student is there. In the distance education, as its name implies, they are distant. In the classroom, you can see what they are doing. You can see what they cannot understand. But here this is not possible; at first the child seems to be listening but then helshe does not participate because helshe cannot catch up with; helshe gets lost (T4)

The student should solve the problem and I need to watch him/her solving the problem and I need to intervene when needed. In Zoom, students respond altogether. For example, one student says I have done it by writing on Chat but I cannot see what helshe has done. In this process, I am not next to the student, I cannot see what helshe is doing, whether helshe is doing true or false and where helshe has a difficulty. Otherwise, helshe would easily progress easily with my help. Here, as students are in a group and I cannot see them as I see in the class, I cannot intervene with individual students. If I ask many questions to a student, helshe may feel worried. (T5)

\section{Student Readiness}

This code is related to students' level of readiness. The teachers' opinions are that students are not ready for distance education process, both psychologically and technologically, because they entered the process suddenly.

We cannot reach children. Children think they're on holiday. Children are not aware that this is also an educational process. The school was closed before the children knew what it was. We could not prepare them. On the last day of the school, most of them went home without even taking their books. Most of the children are like having a holiday. Only those who will take the exam from the $8^{\text {th }}$ graders are active in this process because they have a purpose. But from among them, only the ones feeling motivated for the exam are active. Others seem to be completely lost. (T1)

I actually teach at a school of a higher socio-cultural level. Children have computers etc. Yet, they use their computers for Facebook or to play games. When I tell them to download Zoom, they feel confused as they cannot figure out how to set it up. I need to explain them one by one. For example, there was a student who was good at drawing. We encouraged him to enter competitions like logo competition and he was successful there. But when I wanted him to set up Photoshop program in his computer, he could not do it. Although they were born into the world of computers, their computer skills are not well-developed. As a result, it was really difficult for me to use ClassDojo or another program called "Derslikte" with these students. I am in communication with only $20 \%$ of the students (T4)

\section{School Policies}

Since the transition to the distance education process was very fast as a whole country, the Ministry of National Education did not set standards to be followed by schools in this process rather let them free because the conditions of all schools, teachers and students were not the same. In this context, it is seen that schools and teachers try to manage this process in line with their own means. In this sub-code, the policies of the school and the ministry will be examined.

Not all teachers are teaching but you are and thus students ask "you are teaching your lessons but others aren't, why? This is a serious problem. There is no unity. One teacher says "there is no need" while you say "yes we need to do this". It would be better if a common decision had been made. Now it completely relies on personal efforts and good-will. Our administration let us free to decide whether to teach or not live in the distance education environment. I did not want to leave students on their own. I did not want them to feel as if they were on holiday. On the other hand, this is a strange and challenging process. I decided to teach as I thought that we could see each other, that I could support them and increase their motivation and that they could learn something. In fact, I am making great effort but if some others think it unnecessary, my motivation is negatively affected. (T8) 


\section{Fourth Super-Theme - Psychological Factors}

The codes under this super theme are collected under three sub-themes which are called changing living conditions of teachers in the pandemic, anxiety induced by cyber-bullying and emotional reasons.

\section{Changing Living Conditions of Teachers in the Pandemic}

During the pandemic, as in all people's lives, there occurred some changes in the living conditions of teachers. In this context, psychological situations that prevent teachers from adapting to distance education process are combined around three sub-codes. The first sub-code is the epidemic, the second sub-code is the economic effect of the epidemic and the third sub-code is changing life. Although one of the teachers is living in a small city, she closely witnessed the effects of the epidemic.

I just started my live lesson. I prepared my tablet and computer. One of my neighbours was diagnosed with Covid-19. Health care providers in white dresses came with an ambulance and took him to the hospital. His spouse and children stayed at home. We are using the same environment with them. We are living in the same apartment building. Children go to the garden. My psychology is not good. I have always listening to myselffor three days, cleaning the house, washing my hands. I am worried about being infected. I am always wondering about this. I do not much care about the distance education of children; I just want to get rid of this epidemic. (T15)

Another teacher stated that her husband lost his job in this process. Thus, her performance and motivation decreased because of the economic effects of the epidemic.

My husband lost his job. We have credits to pay. Everyone's income has decreased. I don't have any additional tuition fees. How can we pay our credits when my husband is unemployed? I have a salary but it is not enough. We have serious economic concerns. How will we pay our bills and debts? Everyone is thinking like me. There are concerns. Among these concerns, how can I learn to use web2? With this mood, I do not feel motivated to learn such things. We do not know what this illness is. My mother has a heart problem. As everyone's life has changed profoundly, it is very difficult to adapt to this new process for even educated people. It is not easy to manage this stress. You have to change your old routines. When my husband came home and told me that he lost his job, I was giving my online lesson; I was so shocked that I finished the lesson early. I could not go on. I have been feeling highly confused for three days. I am trying to recover but it is difficult because it directly affects our life. I cannot go out, I feel stressed, I feel tired; how can I teach? (T2)

Due to the epidemic, living conditions of families, people around them and their working conditions have changed. Teachers are directly affected from this.

My mother was looking after my baby. Curfew was declared for a short period of time. My husband is working. My mom is old and taking my baby to her every day means risking her. She cannot come, either. My life has changed dramatically. Since I have a baby at home, I always tell my students to reach me in the evening because if they call me in the morning I cannot attend to them sufficiently. I can talk to them after 9:00 in the evening. Thus, I cannot find enough time. I think I cannot meet their needs. (T3)

\section{Cyber Bullying}

One of the codes in this theme is cyber bullying. This code refers to inability of teachers to adapt to the process due to their concerns about cyber bullying and cyber fraud. Teachers clearly stated that they are afraid of being subjected to cyber bullying.

I am not a kind of person who can comfortably speak to the camera; I would like to be such person but I cannot. I feel tense. I need to see students in the real classroom environment. As a result, I cannot upload YouTube video; I cannot deliver live lessons. There are already ready-to-use lessons. I am just finding them and sending my students because I cannot do it myself. I am not good with the camera. There should be someone who I can interact with. In a live lesson, when you allow all students to speak, you cannot manage it. I am not a person who delivers monotonous lessons. I want to make jokes and I want to laugh and to be laughed. I want to see concrete reactions of students. This is not something I am used to. You need to be still in front of the camera. I do not like it. (T4) 
First of all, I don't want to make a synchronous lesson or a lesson on YouTube. What happened to the English teacher last week is known to everyone (the English teacher was lynched by social media because she spoke like a child while she was teaching on TV and used too many gestures). You make a mistake and you are criticized severely. This is not for everyone. Actually, I wouldn't want to experience that uneasiness. I cannot create a channel open to the public because I cannot trust my students and other people. Some part of my video can be cut off and some other unwanted things can be attached there; thus, something done with a good intention can harm you. How bad things have been told about the English teacher, who was really trying hard to teach something to students. A lot of criticisms. They even criticized him for the colour of the board he used. And he is much more successful than many teachers I know. So I feel uneasy. You deliver spontaneous lesson and the lesson is recorded (synchronous). You say something, you get confused. You can make a mistake. You are laughed at by students. It would not be good for my image as a teacher. (T2)

I feel concerned about security gap. I do not use it. There are free programs but you are sharing your screen and computer. Everyone can easily have access to others' screens. In today's world, there are many cybercrimes. Accordingly, I cannot dare to download them. And I also heard from my friends that 58 dollars were withdrawn from the accounts of some teachers. I am concerned that my credit card information can be stolen. (T6)

\section{Emotional Reasons}

The teachers stated that the distance education process is a process carried out in the computer environment and this process emotionally limited the teachers. All the teachers emphasized that they had difficulty in establishing links and communicating with students during the distance education process.

You also affect the child emotionally in face-to-face education. You have a chance to affect them in every sense. Bu there are no emotional connections in the computer. No emotions. In the classroom, there is energy between you and students. When you cannot establish emotional connections with students, it is more difficult to make them interested in your lesson. Children should realize that they are cared for by the teacher. Here, it is too mechanical. (T2)

I am an emotional person. Teaching is an emotional profession. It is no good without emotions. I cannot do it. I need to laugh, smile, love and they laugh to me, they will respond to my jokes. I establish links with my students in this way. In my opinion, teaching requires feelings. The student needs to love either the teacher or the lesson. Yet, emotions cannot be expressed via the computer. We are highly restricted by it. I do not feel professionally satisfied. (T8)

\section{Fifth Super Theme - Teachers' Readiness}

This super-theme is focused on the readiness of teachers. There are two codes under this theme. First of these codes is related to the technical equipment to be possessed by teachers. All of the teachers mentioned the shortage of technical equipment and lack of materials.

I wish both teachers and students had the necessary software and hardware infrastructure. I was using GeoGebra at school but it is not possible for me to use it at home. Students cannot use it on their phones. They do not have computers. I was using $z$ book in the smart board but this is also not possible at home. (T7)

My computer is old. When I download different programs then it works slowly. I have no camera. I have no tablet. I am trying to do it with my phone. (T6)

The requirements in this system seem to be endless, we continuously need something new. And everything is very expensive now. My computer is new but not touch screen. My phone did not have a pen so I had to buy a new phone. Although my phone is new, I bought a new phone with a bigger screen and pen. (T8)

There is a problem with the hardware. There is not touch screen graph tablet. I have no document camera. I want to buy one but its price increased too much. It was 300 TL but it is 1000 TL now. This is a lot of money for me. (T5) 
The second sub-code is about whether teachers are ready for distance education in terms of their knowledge base. Most of the teachers stated that they are not ready for this process. They said that they are trying to adapt to the process with their own efforts.

We use smart boards in classrooms, but I realized that didn't know anything about distance learning. I even do not know Zoom. I have just looked at it and panicked. I do not have enough knowledge on this issue. (T3)

Teachers do not have any training on this issue. There is a lack of hardware. First we should have been trained for a few weeks about internet-based distance teaching before starting this process. I am trying to learn Zoom with my own efforts through trial and error; I am also trying to learn WEB 2.0 tools. How much can I learn in such a limited time? How effectively can I use them? I have no child; thus, I have limited responsibilities at home. But there are many teachers who cannot spend so much time to learn these. Kahoot! and other Web 2.0 tools work in Zoom. Just textbooks, notebooks and board are not enough for an enriched lesson. If I use a program, they need to have the same program. They have no such programs. Such programs are expensive. Many of them do not have a computer. The teacher and students need to have the same program. And you need to be really good at these programs. Like a DJ you always need to change the material. I am not so knowledgeable. I know how it should be but I do not know how to do it. (T1)

\section{DISCUSSIONS AND CONCLUSION}

In the current study, it was attempted to reveal the mathematics teachers' observations and evaluations of the distance education process in which they were suddenly involved. The teachers stated that the mathematics includes long mental processes and that the student should be activated and followed in this process and that these are not possible in distance education applications. It was emphasized that giving immediate feedback by following the student's actions is very important for the mathematics lesson, but it was stated that there is neither enough time nor suitable conditions to do this in distance education. Also, according to the teachers, the student is passive in live video and EBA TV lessons while he/she is supposed to be active and thus many students easily give up. The teachers stating that in the face-to-face education, they apply different interaction-based teaching methods and materials in the lesson in order to prevent students from getting distracted could not make use of such interactions in video lessons. Murphy (2020) also thinks that the transition to distance education as a result of social isolation will limit face-to-face classroom interactions. This supports the finding of the current study. In this sense, it was noteworthy that the point that teachers frequently emphasized is the limitation of communication and interaction.

Together with the spread of the pandemic all over the world, it was decided to suspend the formal education in the week following the detection of the first COVID-19 case in Turkey and distance education was started. Thus, the Ministry of National Education announced that classes would be conducted over EBA, which serves as a digital education platform. While the teachers interviewed in the current study gave mostly positive opinions about EBA Web contents, they added that there was a lot of trouble in accessing the platform and even there were times when it was never accessible due to overload. Some lessons could not be conducted as students could not access EBA Web. Zhou et al. (2020) emphasized in their study evaluating distance education activities conducted in China that large-scale online education cannot be carried out without a solid infrastructure. Accordingly, it can be concluded that the EBA platform, which was established in 2012 within the scope of FATIH Project, did not reach the desired level of infrastructural efficiency.

The participants stated that they turned to alternative web and communication tools as a result of the problems they experienced in accessing EBA. When the relevant literature is reviewed, it is seen that there are many different applications used worldwide such as Zoom, Slack, Google Meet, EduPage, Google Classroom, WhatsApp, Email, Moodle, Edmodo, ClassDojo, Schoology (Basilaia \&Kvavadze, 2020; Gunawan, Suranti\& Fathoroni, 2020; Syam, Nismawaty\& Hakim, 2020). In the current study, it was determined that the majority of teachers preferred video conferencing applications and the most used video conferencing application was Zoom. In addition, "Derslik", a digital learning platform, was also preferred. However, the teachers stated that they had difficulties in using these applications and platforms. The reasons for these difficulties were found to include insufficiencies in the internet infrastructure, the lack of knowledge 
and experience of teachers and students, and the limited use of computers, tablets or phones in students' homes. Moreover, a teacher emphasized that the language of many digital education platforms is English and that the number of Turkish platforms should be increased.

It was seen that all of the teachers participating in the study used WhatsApp, an instant messaging application, as a way of communicating with students. In the study conducted by Gunawan et al (2020), it was observed that it is the most used application by instructors as communication and education platform during the COVID-19 pandemic thus, the findings of the two studies seem to concur with each other. The teachers said that they set up various groups in WhatsApp, which they used to respond to the problems and needs of the students quickly, to assign daily homework and to share videos showing problem solutions. The popular use of WhatsApp as a distance learning tool was found to be interesting. But they also emphasized that there is intense traffic here and they often find it difficult to follow incoming messages.

During the pandemic, all of the GSM operators gave all users the 8 GB internet package for EBA Web. However, according to the teachers, the $8 \mathrm{~GB}$ internet package given to a single user was not sufficient in houses with more than one child, which caused many students to stay away from the education process. Telli Yamamoto and Altun (2020) emphasized that students who have financial difficulties encounter difficulties in accessing the internet and following the lessons accordingly. This finding concurs with the finding of the current study. This process is troublesome for students who do not have a computer and a tablet at home and who try to attend classes on their parents' phone. In this context, it can be concluded that the problem of inequality of opportunity arises in the process of using both EBA and alternative platforms as a distance education application.

Parent profile was also found to be important for the teachers because during the period of pandemic when they stay at home with their children, parents are expected to manage the distance education process. According to teachers, students can be successful in distance education in families with high education level and interested in their children. On the contrary, in families that are indifferent to their children, children do not participate in any way. Apart from the indifferent family factor, another factor that causes the student to move away from the lessons is the failure to provide the desired support to the students who are below the class average. The teachers emphasized that they follow the lower level students more closely in the face-toface classroom education and that they try to draw their attention to the lesson and ask questions that are appropriate for their level. However, since they cannot provide these opportunities in distance education, the lower level students have the feeling of failure and do not attend the lessons. Here it is interesting that according to the teachers, distance education moves away the average and below average students from the education process.

It has been observed that there are factors that decrease the motivation of teachers in the distance education process. One teacher stated that many teachers do not teach their lessons as the conduct of distance education process is left to the discretion of the school administration and teachers, and that this has negative effects on students, and that although he makes large amount of effort, the lack of unity in applications decreases her motivation. This statement of the teacher shows that there are no specific and common practices in distance education and some of the teachers do not perform their duties unless an obligation is imposed.

Another factor that lowers the motivation of the teachers is the concerns about the health and economic situation. A teacher stated that as she witnessed a case infected with the highly contagious COVID-19 pandemic in her close vicinity, she could not continue distance education in fear and anxiety. Another teacher stated that she was unable to focus on giving lessons due to economic difficulties as a result of her husband's dismissal during the pandemic. These show that the COVID-19 pandemic affects teachers negatively and prevents them from performing their jobs efficiently.

As a result, in light of the opinions of the participating teachers, it has been revealed that mathematics lesson is not suitable to be carried out with distance education applications, teachers have difficulties in interacting and communicating with students, because of the limited interaction and lack of immediate feedback, some students stay completely away from the lessons, there is lack of information about the use of internet and technological tools, there are significant insufficiencies throughout the country in terms of hardware and infrastructure, inequality of opportunity occurs in the distance education process, COVID-19 disease causes fear and anxiety, and the motivation of teachers and students decreases accordingly. 


\section{BIODATA and CONTACT ADDRESSES of AUTHORS}

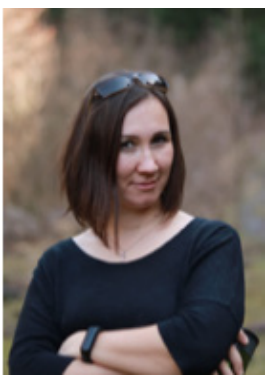

Dr. Seyma SENGIL AKAR, is assistant professor at Kastamonu University, Faculty of Education, Department of Elementary Education. Her PhD emphasis on Mathematics Education. Her academic interests are mathematics education, gifted education, mathematical modeling (MEA), mathematical creativity. She has articles, book chapters and presentations on these topics.

Seyma SENGIL AKAR

Kastamonu University

Address: Faculty of Education, Department of Elementary Education

Kastamonu University, Kastamonu, Turkey.

E-mail: seymasengil@gmail.com

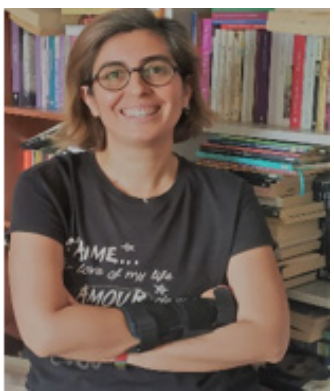

Dr. Meltem KURTOGLU ERDEN, is an assistant professor at the Department of Computer Education and Instructional Technology (CEIT) at Faculty of Education at Usak University in Usak. She received her doctoral degree at the department of CEIT at Hacettepe University. Her academic interest areas are teacher education, educational technology, instructional design, technology integration, using technology in teaching and learning process. She has over than 10 journal articles published in national and international indexes, 3 national book chapters. Also she has lots of presentations at national and international meetings.

Meltem KURTOGLU ERDEN

Department of Computer Education and Instructional Technology (CEIT)

Faculty of Education University of Usak.

Address: University of Usak, 64200, Usak, Turkey.

Phone: 02762212121

E-mail: meltem.kurtoglu@usak.edu.tr

\section{REFERENCES}

Alpago, H. \& Alpago, D. O. (2020) Korona Virus ve Sosyoekonomik Sonuclar. IBAD Sosyal Bilimler Dergisi, (8), 99-114. https://doi.org/10.21733/ibad.716444

Arat, T. \& Bakan, O. (2011). Uzaktan Egitim ve Uygulamalari. Selcuk Universitesi Sosyal Bilimler Meslek Yuksek Okulu Dergisi, 365, 14(1-2).

Basilaia, G., \& Kvavadze, D. (2020). Transition to Online Education in Schools during a SARS-CoV-2 Coronavirus (COVID-19) Pandemic in Georgia. Pedagogical Research, 5(4), em0060. https:// doi.org/10.29333/pr/7937

Chick, R. C., Clifton, G. T., Peace, K. M., Propper, B. W., Hale, D. F., Alseidi, A. A. ve Vreeland, T. J. (2020). Using technology to maintain the education of residents during the COVID-19 pandemic. Journal of Surgical Education. https://doi.org/10.1016/j.jsurg.2020.03.018

Clandinin, D. J., \& Connelly, F. M. (2000). Narrative inquiry: Experience and story in qualitative research.

Creswell, J. W. (2013). Qualitative inquiry: Choosing among five approaches. Los Angeles, CA, 244.

Ferguson, S. (2020) Attrition in Online and Face-to-Face Calculus and Precalculus Courses: A Comparative Analysis. Journal of Educators Online, (17/1) 2020 
Gunawan, G., Suranti, N. M. Y., \& Fathoroni, F. (2020). Variations of Models and Learning Platforms for Prospective Teachers During the COVID-19 Pandemic Period. Indonesian Journal of Teacher Education, 1(2), 61-70.

Smith, G.G., \& Ferguson, D. (2005). Student attrition in mathematics e-learning. Australian Journal of Educational Technology.1(3), 323-334. https://ajet.org.au/index.php/AJET/article/ view/1323/694 https://doi.org/10.14742/ajet.1323

Micari, M., G. Light, S. Calkins, \& B. Streitwieser. 2007. Assessment beyond performance. American Journal of Evaluation. 28(4): 458-476. https://doi.org/10.1177\%2F1098214007308024

Milli Egitim Bakanligi (Ministry of National Education) official web page. Retrieved on May 05.2020, from: https://www.meb.gov.tr/bakan-selcuk-23-martta-baslayacak-uzaktan-egitime-iliskin-detaylarianlatti/haber/20554/tr

Moreno, J. M. \& Gortazar, L. (2020). Schools' readiness for digital learning in the eyes of principals. An analysis from PISA 2018 and its implications for the COVID19 (Coronavirus) crisis response. WorldBankBlogs.https://blogs.worldbank.org/education/schools-readiness-digital-learning-eyesprincipals-analysis-pisa-2018-and-its 29.08.2020 tarihinde ulasildi.

Murphy, M. P. (2020). COVID-19 and emergency eLearning: Consequences of the securitization of higher education for post-pandemic pedagogy. Contemporary Security Policy, 1-14.https://doi.org/10.1 $080 / 13523260.2020 .1761749$

Ng, Y. M. \&Peggy, P. L. (2020). Coronavirus disease (COVID-19) prevention: Virtual classroom education for hand hygiene. Nurse Education in Practice, 45. Doi: https://doi.org/10.1016/j. nepr.2020.102782.

Ozer, M. (2020). Turkiye'de COVID-19 Salgini Surecinde Milli Egitim Bakanligi Tarafindan Atilan Politika Adimlari Educational Policy Actions by the Ministry of National Education in the times of COVID-19. Kastamonu Education Journal, 28(3), 1124-1129. doi: 10.24106/kefdergi.722280

Patton, M. Q. (2018). Nitel arastirma ve degerlendirme yontemleri (2. Baski). Cev. Ed. M. Butun, SB Demir). Ankara: Pegem Akademi.

Parker, D. \&Gemino, A.(2001). Inside online learning: Comparing conceptual and technique learning performance in place-based and ALN formats. Journal of Asynchronous Learning Networks. 5(2): $64-74$

Patterson, B., \& McFadden, C. (2009). Attrition in online and campus degree programs. Online Journal of Distance Learning Administration, 12(2), 1-8.

Setiawan, A. R. (2020). Scientific Literacy Worksheets for Distance Learning in the Topic of Coronavirus 2019 (COVID-19). Doi: https://doi.org/10.31004/edukatif.v2i1.xx

Sintema, E. J. (2020). Effect of COVID-19 on the Performance of Grade 12 Students: Implications for STEM Education. Eurasia Journal of Mathematics, Science and Technology Education, 16(7), em1851.

Syam, H., Nismawaty, R. ve Hakim, H. (2020). Implementation of COVID-19 Preparedness and Prevention Policy at Makassar State University. Doi: http://dx.doi.org/10.2139/ssrn.3590710

Telli Yamamoto, S. ve Altun, D. (2020). Coronavirus ve Cevrimici (Online) Egitimin Onlenemeyen Yukselisi. Universite Arastirmalari Dergisi , 3 (1) , 25-34 . DOI: 10.32329/uad.711110

Trenholm, S., Peshcke, S., \& Chinnappan, M. (2019) A Review of Fully Online Undergraduate Mathematics Instruction through the Lens of Large-Scale Research (2000-2015). Journal of Problems, Resources, and Issues in Mathematics Undergraduate Studies ,29(10). https://www.tandfonline. com/doi/pdf/10.1080/10511970.2018.1472685?needAccess=true

UNESCO (2020), COVID-19: 10 Recommendations to plan distance learning solutions, retrived from https://en.unesco.org/news/covid-19-10-recommendations-plan-distance-learning-solutions on 20.05.2020. 
Ustun, C. \& Ozciftci, S. (2020). COVID-19 Pandemisinin Sosyal Yasam ve Etik Duzlem Uzerine Etkileri: Bir Degerlendirme Calismasi. Anatolian Clinic the Journal of Medical Sciences, 25 (Supplement 1), 142-153 . DOI: 10.21673/anadoluklin.721864

Van Lancker, W. \& Parolin, Z. (2020). COVID-19, school closures, and child poverty: a social crisis in the making. The Lancet Public Health, 5(5), e243-e244. https://doi.org/10.1016/S24682667(20)30084-0

Xu, D., \& Jaggars, S. (2014). Performance gaps between online and face-to-face courses: Differences across types of students and academic subject areas. The Journal of Higher Education, 85(5), 633-659. doi:10.1080/00221546.2014.117 77343

Zhou, L., Wu, S., Zhou, M. \& Li, F., 'School's Out, But Class' On', The Largest Online Education in the World Today: Taking China's Practical Exploration During The COVID-19 Epidemic Prevention and Control As an Example (March 15, 2020). Best Evid Chin Edu 2020; 4(2):501-519. , doi: http://dx.doi.org/10.2139/ssrn.3555520 